\title{
Normal Human Epidermal Keratinocytes Express In Vitro Specific Molecular Forms of (Pro)Filaggrin Recognized by Rheumatoid Arthritis-Associated Antifilaggrin Autoantibodies
}

\author{
Elisabeth Girbal-Neuhauser, Martine Montézin, \\ Françoise Croute, Mireille Sebbag, Michel Simon, \\ Jean-Jacques Durieux, and Guy Serre \\ Department of Biology and Pathology of the Cell, Toulouse-Purpan \\ School of Medicine, INSERM CJF 96-02, IFR 30, University of \\ Toulouse III, Toulouse, France
}

\begin{abstract}
Background: The so-called antikeratin antibodies and the antiperinuclear factor are the most specific serological markers of rheumatoid arthritis (RA). They were recently shown to be largely the same autoantibodies and to recognize human epidermal filaggrins and profilaggrin-related proteins of buccal epithelial cells (collectively referred to as (pro)filaggrin).

Materials and Methods: To further characterize the target antigens, we investigated their expression by normal human epidermal keratinocytes cultured in differentiating conditions, using immunofluorescence and immunoblotting with RA sera and three different monoclonal antibodies to (pro)filaggrin.

Results: On the cornified, stratified epithelial sheets obtained in vitro, RA sera with anti(pro)filaggrin autoantibodies (AFA) produced granular staining of the stratum granulosum and diffuse staining of the stratum corneum. The antigens recognized by RA sera strictly colocalized
\end{abstract}

with (pro)filaggrin in keratohyalin granules. Following sequential extraction of the proteins from the epithelial sheets, the RA sera and the three monoclonal antibodies to (pro)filaggrin, recognized a series of low-salt-soluble molecules, including a neutral/acidic isoform of filaggrin and several proteins with sizes and $\mathrm{pI}$ intermediates between this isoform and profilaggrin. They also recognized urea-soluble high-molecular-weight profilaggrinrelated molecules.

Conclusions: These results show that in vitro epidermal keratinocytes express various molecular forms of (pro) filaggrin that bear epitopes targeted by AFA of RA sera, and that some of these are absent from epidermis. Moreover, these epitopes, which are present on the keratohyalin granules of buccal epithelial cells but not on those of epidermal cells, are present on the granules of the cultured keratinocytes. This work completes the molecular characterization of the proteins targeted by AFA.

\section{INTRODUCTION}

Numerous circulating antibodies, including rheumatoid factors ( 1 ) and antibodies to various cellular components $(2,3)$ have been described in sera from patients with rheumatoid arthritis (RA). Most of the antibodies, however, are also

Address correspondence and reprint requests to: Pr. Guy Serre, Laboratoire de Biologie Cellulaire, C.H.U. Purpan, Place du Dr. Baylac, 31059 Toulouse cedex, France. present in sera from patients with other autoimmune diseases and therefore cannot be used as reliable criteria for the diagnosis of RA. An exception is the antiperinuclear factor that decorates perinuclear granules in the superficial cells of the human buccal mucosa epithelium, which for 30 years has been considered to be specifically associated with RA $(4,5)$. Similarly, the G immunoglobulins, first described by Young et al. (6) to label the stratum corneum of the rat esophagus 
epithelium and called "antikeratin antibodies," have also been found to be highly specific markers of the disease $(5,7-10)$. Recent evidence has indicated that antikeratin antibodies and the antiperinuclear factor are essentially the same autoantibodies (11). These genuine autoantibodies, which also label the stratum corneum of human epidermis $(6,12-14)$, have been detected with high titers in rheumatoid synovial fluids $(7,15)$ and have been shown to appear precociously and even precede the clinical symptoms of the disease $(16,17)$. This suggests that these autoantibodies could be involved in the pathophysiology of RA.

Characterization of the rat esophagus epithelial antigens showed that these antibodies do not recognize cytokeratins, the major protein component of the stratum corneum, but rather, three late epithelial differentiation proteins immunologically related to rat (pro)filaggrin (18). In the stratum corneum of human epidermis, evidence including data from immunoabsorption experiments indicates that the epidermal filament-aggregating protein filaggrin and its neutral/acidic isoform are the targets of these antibodies (19). Moreover, these antibodies also detect (pro)filaggrin-related proteins in buccal epithelial cells. Based on these data, we propose naming them "antifilaggrin autoantibodies" (AFA) (11).

Filaggrin is a histidine-rich cationic protein present in the cornified layers of mammalian epidermis $(20,21)$. It is synthesized in the stratum granulosum, the epidermal layer located just below the stratum corneum, as a high-molecular-weight phosphorylated precursor, profilaggrin, consisting of 10 to 12 filaggrin units separated by linker peptides. This precursor is located in the keratohyalin granules of the stratum granulosum and is processed into filaggrin monomers by dephosphorylation and proteolysis (22-24). Extraction from epidermis of profilaggrin and of the mature basic filaggrin, which aggregates the cytokeratins, requires high urea concentrations, whereas isolation of the neutral/ acidic isoform of filaggrin can be achieved using a low-salt buffer (19). All of these forms are collectively referred to as (pro)filaggrin.

A recent study showed that epidermal profilaggrin is not recognized by RA sera (12). Furthermore, in the noncornified buccal epithelium, the molecule recognized by RA sera corresponds neither to epidermal profilaggrin nor to any of the isoforms of filaggrin described above but to a modified profilaggrin (11).

To further characterize the (pro)filaggrin- borne RA-associated antigens, we analyzed their in vitro expression by human epidermal keratinocytes. The cells were cultured in conditions allowing expression of the terminal differentiation program up to cornification $(25,26)$ and thus the synthesis of the late differentiation proteins including (pro)filaggrin. Using selected RA sera and original mouse monoclonal antibodies directed to human epidermal (pro)filaggrin (27), we analyzed the histological location of the targeted molecules by indirect immunofluorescence and described their characteristics by sequential extractions and immunoblotting.

\section{MATERIALS AND METHODS Cultures}

Culture of normal human keratinocytes was performed as previously described (28) with some modifications. Briefly, breast skin samples were obtained from plastic surgery and cultured on mitomycin C-treated 3T3 feeder layer according to Rheinwald and Green $(25,26)$. The culture medium consisted of Dulbecco's modified Eagle medium (DMEM) and Ham F12 (v/v:5/1, Gibco BRL, Life Technologies, Paisley, Scotland) supplemented with $0.4 \mu \mathrm{g} / \mathrm{ml}$ hydrocortisone, $2 \times$ $10^{-9} \mathrm{M}$ triiodothyronine, $10^{-10} \mathrm{M}$ cholera toxin, $5 \mu \mathrm{g} / \mathrm{ml}$ insulin, $1.2 \mathrm{mg} / \mathrm{ml}$ adenine, $5 \mathrm{mg} / \mathrm{ml}$ human transferrin (Sigma, St Louis, MO), $50 \mathrm{U} / \mathrm{ml}$ streptomycin/penicillin (Gibco BRL) and $10 \%$ heat-inactivated fetal calf serum (FCS; Institut Jacques Boy S.A., Reims, France). The medium was changed at Days 2, 4, 6, 8, and 10. From Day 2 to Day 12, epidermal growth factor (Sigma) was added at a final concentration of 10 $\mathrm{ng} / \mathrm{ml}$. When the keratinocytes reached confluence (Day 12), they were further cultured for 7 days in retinoic acid-free medium to induce keratinocyte differentiation. This medium was the same as above except that the FCS, which was heat-inactivated then depleted in retinoic acid by delipidization (29), was used at only $5 \%$. The culture medium was renewed at Days 14, 16, and 18.

\section{Human Sera and Monoclonal Antibodies}

Human sera were obtained from four healthy donors (control sera) and from eight patients with RA classified according to the criteria of the American Rheumatism Association (30). We chose RA sera with a high titer of antikeratin 
antibodies, and with a low titer of naturally occurring autoantibodies to cytokeratins assayed by indirect immunoflorescence and ELISA, respectively, as previously described $(10,13)$. Their reactivity to human filaggrin was confirmed by immunoblotting as previously reported (19). The murine monoclonal antibody (MAb) AKH l (IgG l, ascitic fluid), specific for human epidermal filaggrin and profilaggrin (31), was purchased from Biomedical Technologies (Stoughton, MA). The two MAbs AHF1 and AHF7 (IgG1) are part of a series of seven MAbs to human (pro)filaggrin recently produced and characterized in our laboratory (27). AHFl specifically recognizes filaggrin and its precursor, while AHF7 only recognizes filaggrin. EE21-06, a murine MAb also produced in our laboratory, is directed against an epitope shared by the human cytokeratins $\mathrm{Kl}$, $\mathrm{K} 2$, K9, and K10/11 (32).

\section{Histology}

Cultured keratinocytes were detached from flask bottoms with dispase $(2.4 \mathrm{U} / \mathrm{ml}$; Boehringer Mannheim, Mannheim, Germany). Culture sheets were fixed for $24 \mathrm{hr}$ in Dubosq-Brasil solution ( $45 \%$ ethanol $\mathrm{v} / \mathrm{v}, 0.45 \%$ picric acid $\mathrm{w} / \mathrm{v}, 36 \%$ formol $v / v, 7 \%$ acetic acid $v / v)$, paraffin embedded, and cut into $4-\mu \mathrm{m}$ sections. The sections were deparaffinized in toluene, rehydrated in a graded series of ethanol, and stained with hemalum-eosin. The slides were observed with an Olympus BH-2 microscope (Tokyo, Japan).

\section{Immunohistology}

Dispase-treated epidermal sheets and normal human skin were frozen embedded in Tissue-Tek medium (Reichert-Jung, Heildeberg, Germany), cut into $4-\mu \mathrm{m}$ sections, and stored at $-30^{\circ} \mathrm{C}$ until used. Indirect immunoflorescence was performed as previously described $(13,28)$. Briefly, the first antibodies diluted in phosphate-buffered saline (PBS; $150 \mathrm{mM} \mathrm{NaCl}, 7 \mathrm{mM} \mathrm{K} \mathrm{K}_{2} \mathrm{HPO}$, $1.5 \mathrm{mM} \mathrm{KH}_{2} \mathrm{PO}$, $\mathrm{pH} 7.4$ ), were incubated for $45 \mathrm{~min}$ at $37^{\circ} \mathrm{C}$; human sera were diluted to $1: 50$, AKH1 to 1:200, AHF1, AHF7 and EE21-06 to $5 \mu \mathrm{g} / \mathrm{ml}$. After washing, sections were incubated for $30 \mathrm{~min}$ in the same conditions with the relevant fluorescein isothiocyanate-labeled antibodies diluted in PBS: either goat antibodies to mouse IgG (Southern Biotech, Birmingham, $\mathrm{AL}$ ) diluted to $1: 200$ or goat antibodies to human immunoglobulin heavy chains (Biosys, Compiègne, France) diluted to 1:100. The slides were then mounted with Fluoprep medium (Biomérieux, Marcy l'Etoile, France) and observed under an Olympus BH-2 microscope with UV epi-illumination. For double staining experiments, sections were first incubated with AKHI and revealed with tetramethylrhodamine isothiocyanate-labeled goat antibodies to mouse IgG (Sigma). After washing, the slides were incubated for $20 \mathrm{~min}$ at $37^{\circ} \mathrm{C}$ with an RA serum, and human IgG were detected with the fluorescein isothiocyanate-labeled goat antibodies to human IgG.

\section{Sequential Protein Extraction}

Frozen skin fragments were incubated for $5 \mathrm{~min}$ at $56^{\circ} \mathrm{C}$ in PBS containing $0.5 \mathrm{mM}$ phenylmethylsulfonyl fluoride and $5 \mathrm{mM}$ EDTA. A second incubation in the same buffer without EDTA was performed for $5 \mathrm{~min}$ at $4^{\circ} \mathrm{C}$. Epidermis was then easily separated from dermis with forceps. Cultured keratinocytes were detached by scraping, centrifuged for $10 \mathrm{~min}$ at $200 \times g$ and the pellet frozen at $-30^{\circ} \mathrm{C}$. For sequential protein extractions, human epidermis or cultured keratinocytes were homogenized on ice in $40 \mathrm{mM}$ Tris$\mathrm{HCl}, \mathrm{pH} 7.4,150 \mathrm{mM} \mathrm{NaCl}, 5 \mathrm{mM}$ EDTA, $0.5 \%$ Nonidet P-40, $0.1 \mathrm{mM}$ phenylmethylsulfonyl fluoride, and $2 \mu \mathrm{g} / \mathrm{ml}$ pepstatin A. The lysates were centrifuged at $15,000 \times g$ for $15 \mathrm{~min}$ at $4^{\circ} \mathrm{C}$ and the supernatants ("low-salt extracts") were recovered and kept at $-30^{\circ} \mathrm{C}$. The pellets underwent the same treatment twice. Then they were homogenized on ice in $50 \mathrm{mM}$ Tris- $\mathrm{HCl}, \mathrm{pH} 7.6$, $10 \mathrm{mM}$ EDTA, $8 \mathrm{M}$ urea, $0.1 \mathrm{mM}$ phenylmethylsulfonyl fluoride, and $2 \mu \mathrm{g} / \mathrm{ml}$ pepstatin $\mathrm{A}$. The suspensions were centrifuged at $15,000 \times g$ for $15 \mathrm{~min}$ at $4^{\circ} \mathrm{C}$ and the new supernatants ("urea extracts") were recovered and stored at $-30^{\circ} \mathrm{C}$. Protein concentrations were measured using the Coomassie Plus protein assay (Pierce, Rockford, IL).

\section{Electrophoreses}

Proteins of the low-salt extracts were precipitated by ethanol and collected by centrifugation. For one-dimensional electrophoresis, dried pellets were dissolved in $10 \mathrm{mM}$ Tris- $\mathrm{HCl}, \mathrm{pH} 7.4$, $2 \%$ SDS, $1 \%$ 2-mercaptoethanol, and $0.01 \%$ bromophenol blue. For two-dimensional electrophoresis, pellets were dissolved in distilled water with $0.01 \%$ bromophenol blue. Proteins of the urea extracts were precipitated by acetone and collected by centrifugation. For one-dimensional 
electrophoresis, dried pellets were dissolved in $20 \mathrm{mM}$ Tris- $\mathrm{HCl}, \mathrm{pH}$ 7.6, $6 \mathrm{M}$ urea, 4\% SDS, $1 \%$ 2-mercaptoethanol, and $0.01 \%$ bromophenol blue. For two-dimensional electrophoresis, pellets were dissolved in $50 \mathrm{mM}$ Tris- $\mathrm{HCl}, \mathrm{pH} 7.6$, $8 \mathrm{M}$ urea, and $0.01 \%$ bromophenol blue. SDSPAGE was performed using a PhastSystem (Pharmacia, Uppsala, Sweden) with precast $8-25 \%$ polyacrylamide gels following the procedures suggested by the manufacturer. Protein markers from Bio-Rad Laboratories (Richmond, CA) were used as molecular weight references. For twodimensional electrophoresis of the low-salt extracts, proteins were separated by isoelectrofocusing in the first dimension using PhastGels with ampholytes generating a 3-9 $\mathrm{pH}$ gradient. The isoelectrofocusing calibration kit from Pharmacia was used as an isoelectric point (pI) reference. Proteins from the urea extracts were separated by nonequilibrium $\mathrm{pH}$ gel electrophoresis in the first dimension because with isoelectrofocusing, the very basic filaggrin would migrate out of the gel. PhastGels were dried and rehydrated in $6 \mathrm{M}$ urea, $0.5 \%$ Nonidet P-40, containing ampholytes generating a $5-8 \mathrm{pH}$ gradient as described by the manufacturer. The two-dimensional calibration kit of Bio-Rad was used to assess the pI of the proteins. SDS-PAGE was performed in the second dimension.

\section{Immunoblotting}

After electrophoresis, proteins were electrotransferred onto nitrocellulose. They were probed as previously reported (28): briefly, membranes were incubated in blocking buffer $(10 \mathrm{mM}$ Tris$\mathrm{HCl}, \mathrm{pH} 8,150 \mathrm{mM} \mathrm{NaCl}$ with $0.05 \%$ Tween 20 , and $0.5 \%$ skimmed dried milk). Nitrocellulose membranes were incubated overnight with the first antibodies diluted in blocking buffer (AKH1 and human sera were diluted to 1:100, AHF1 and AHF7 at $5 \mu \mathrm{g} / \mathrm{ml}$, and EE21-06 at $2.5 \mu \mathrm{g} /$ $\mathrm{ml})$. After exhaustive washing in blocking buffer, the membranes were incubated for 90 min with the second antibodies diluted in blocking buffer: peroxidase-conjugated rabbit $F\left(a b^{\prime}\right)_{2}$ fragments to mouse IgG (Zymed, San Francisco, CA) diluted to $1: 200$, or peroxidase-conjugated goat antibodies to human IgG (Southern Biotechnology) diluted to 1:400. Peroxidase was visualized with 4-chloro-1-naphthol (Bio-Rad). Alternatively, after nonequilibrium $\mathrm{pH}$ gel electrophoresis/SDS-PAGE, immunoblotting was performed with the ECL Western blotting method (Amersham, Buckinghamshire, U.K.), following the procedures suggested by the manufacturer. AHF1 and AHF7 were used at $600 \mathrm{ng} / \mathrm{ml}$ and $1 \mu \mathrm{g} / \mathrm{ml}$, respectively. AKHl was diluted to $1: 1,000$, human sera were diluted to $1: 250$, and secondary antibodies were used at 1:2,000.

\section{RESULTS}

\section{Histological Observations}

After 19 days of culture, including 7 days in differentiating conditions, keratinocytes constituted stratified and morphologically differentiated epidermal sheets. All layers of normal epidermis were present, in particular, a stratum granulosum that contained numerous keratohyalin granules and a stratum corneum of rather heterogeneous thickness with one to four layer(s) of corneocytes. In contrast to normal epidermis, some of the corneocytes were parakeratotic, containing pycnotic nuclei (Fig. 1).

\section{Immunohistological Observations}

RHEUMATOID ARTHRITIS SERA (FIG. 1). In the cultured epidermal sheets, the eight RA sera tested recognized granules in the granular layers and diffusely stained the stratum corneum. This pattern was very different from that obtained using the same sera on normal human epidermis, where only the stratum corneum was intensely and diffusely labeled. The normal control sera only produced weak and diffuse labeling of the cytoplasm of living cells, both in the cultured keratinocytes and in human epidermis (not shown), due to the low-titered autoantibodies to epidermal cytokeratins (13).

MONOCLONAL ANTIBODIES (FIG. 1). Antibodies AKHl (not shown) and AHFl, directed against both profilaggrin and filaggrin, and AHF7, only directed against filaggrin, produced an intense, granular labeling in the stratum granulosum in the cultured epidermis. The labeling was also present, although weaker and more diffuse, in the stratum corneum. In normal epidermis, AKHl (not shown) and AHFl strongly stained the keratohyalin granules and, in a more diffuse manner, the lower part of the cornified layer, whereas AHF7 only stained the stratum corneum and did not recognize the keratohyalin granules. 
CULTURES
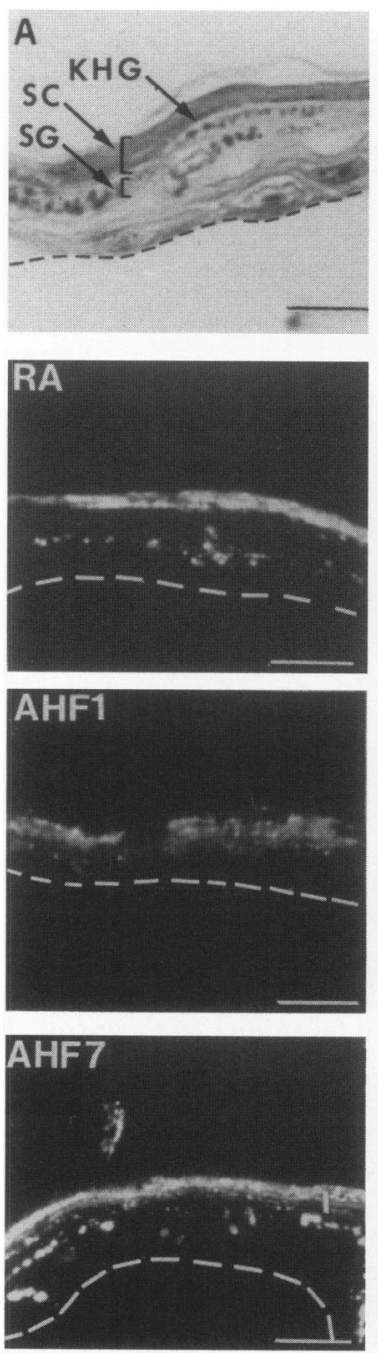

EPIDERMIS
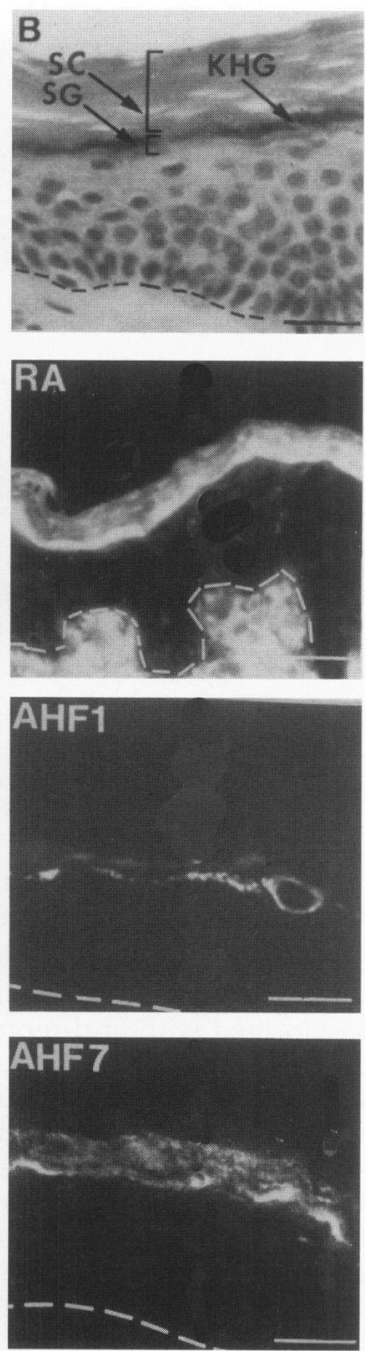

FIG. 1. Histological features and indirect immunoflorescence analysis of cultured human keratinocytes (left) and normal human epidermis (right) using an RA serum and MAbs AHF1 and AHF7 directed toward (pro)filaggrin and filaggrin, respectively

Cultured epithelial sheets (A) show a stratified architecture similar to that of normal epidermis (B). In the cultured epithelial sheets, the RA serum and the AHF MAbs produce labeling that is diffuse and of varying intensity in the stratum corneum and always intense and granular in the stratum granulosum where it labels the keratohyalin granules. In normal epidermis, the RA serum produces laminated labeling restricted to the stratum corneum, AHFl stains the keratohyalin granules of the stratum granulosum and weakly recognizes the lower cornified layers of the stratum corneum, and the filaggrin-specific MAb AHF7 only stains the stratum corneum. Dotted lines denote the dermo-epidermal junction or the basal limit of the cultured epithelial sheets. SC, stratum corneum; SG, stratum granulosum; KHG, keratohyalin granules. Bars = $50 \mu \mathrm{m}$ except in $\mathrm{B}=100 \mu \mathrm{m}$.

AKH1
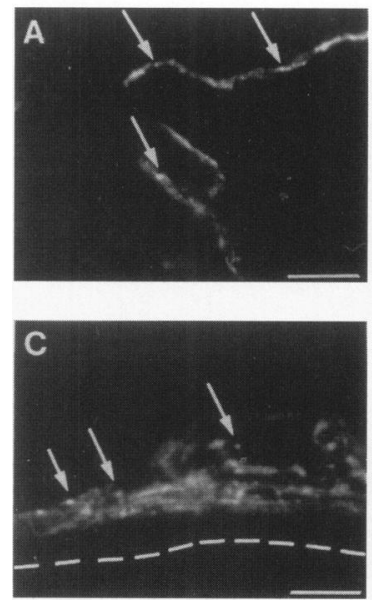

RA SERUM
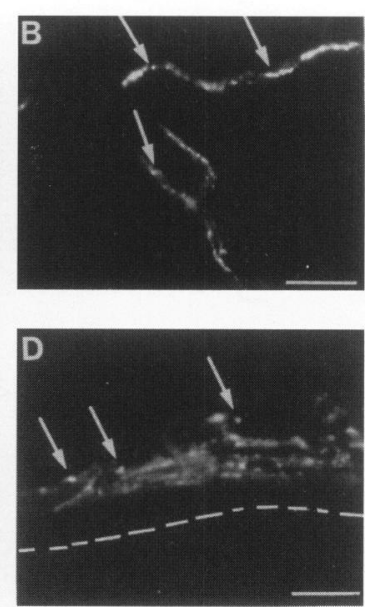

FIG. 2. Double indirect immunoflorescence analysis of cultured human keratinocytes with AKH1, a MAb to (pro)filaggrin, and an RA serum

The labeling of AKHl is revealed with tetramethylrhodamine isothiocyanate-conjugated anti-mouse $\operatorname{IgG}(\mathrm{A}, \mathrm{C})$ and that of the RA serum with fluorescein isothiocyanate-conjugated anti-human IgG (B, D). The MAb and the RA serum label the same granules (arrows). Dotted lines denote the basal limit of the cultured epithelial sheets. Bar $=200 \mu \mathrm{m}$ (A, B); $50 \mu \mathrm{m}(\mathrm{C}, \mathrm{D})$.

DOUBLE STAINING WITH RHEUMATOID ARTHRITIS SERA $A N D A K H 1$ (FIG. 2). Since in cultured epidermal sheets the indirect immunoflorescence distributions of RA-associated antigens and of (pro)filaggrin were similar, we localized them by double indirect immunoflorescence staining using an RA serum and AKH1. The RA-associated antigens and (pro)filaggrin colocalized in the keratohyalin granules of the epidermal sheet granular layer. When a thick stratum corneum was present, the antigens also colocalized at this level (not shown).

\section{Immunochemical Studies}

ONE-DIMENSIONAL IMMUNOBLOTTING ANALYSIS (FIG. 3). The RA sera and all the anti(pro)filaggrin MAbs showed the same reactivity to the low-salt extracts obtained from cultured keratinocytes. They recognized an antigen ranging in size from $\sim 70 \mathrm{kDa}$ to $>200 \mathrm{kDa}$, and additional bands at 40-43 kDa. This reactivity was observed neither with the control sera nor with the control MAb EE21-06. In the low-salt extracts of epidermis, 


\section{CULTURES}
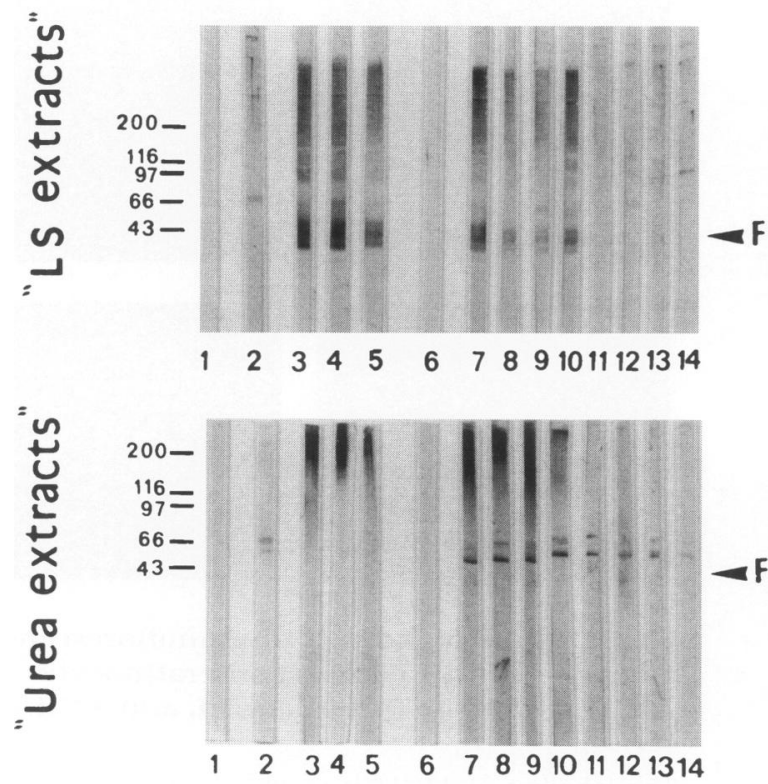

\section{EPIDERMIS}
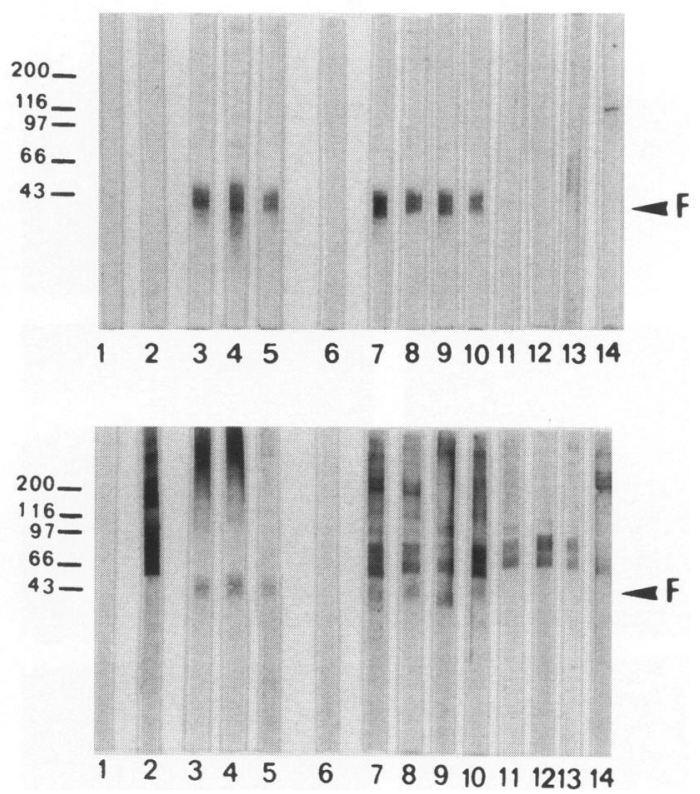

FIG. 3. One-dimensional immunoblotting reactivity of MAbs, RA sera, and control sera to proteins extracted with low-salt buffer or with urea from cultured keratinocytes and normal human epidermis Proteins were extracted either with a low-salt buffer ("LS extracts") or with high concentrations of urea ("Urea extracts"), from cultured keratinocytes (left) and from normal human epidermis (right). In each case, after SDSPAGE, immunoblotting analysis of the extracted proteins was performed with anti-mouse IgG alone as a control (lane 1); EE2 1-06, a MAb to cytokeratins 1, 2, 10/11 (lane 2); AKH1 and AHF1, MAbs to (pro)filaggrin (lanes 3, 4); AHF7, a MAb to filaggrin (lane 5); anti-human IgG alone as a control (lane 6); RA sera (lanes 7-10); normal human sera (lanes 11-14). Within the LS extracts, the RA sera and the anti(pro)filaggrin MAbs detect both 40-43 $\mathrm{kDa}$ bands and a diffuse high-molecular-weight antigen from 70 up to $200 \mathrm{kDa}$ and above in the cultured keratinocytes, while only a diffuse $40 \mathrm{kDa}$ band corresponding to the neutral/acidic isoform of filaggrin is detected in normal epidermis. Within the urea extracts, the RA sera and the anti(pro)filaggrin monoclonal antibodies reveal a diffuse antigen with molecular weight $>100 \mathrm{kDa}$ in the cultured keratinocytes, while they all detect the urea-soluble filaggrin in normal epidermis, AKHI and AHFl showing an additional diffuse reactivity towards the urea-soluble precursor profilaggrin. Note that in the urea extracts, EE21-06 as well as human sera are reactive towards cytokeratins in the $50-66 \mathrm{kDa}$ zone (lanes 2, 7-14); in extracts of normal epidermis, some of them are also reactive towards aggregated cytokeratins in the $66-200 \mathrm{kDa}$ zone (lanes 2, 7-10, 14). Molecular weight markers are on the left of each series of immunoblots. The migration of filaggrin is indicated on the right (arrow, F).

the RA sera and all the anti(pro)filaggrin MAbs recognized only a diffuse band at around $40 \mathrm{kDa}$, which corresponds to the low-salt-soluble neutral/acidic isoform of epidermal filaggrin (19).

In the urea extracts from cultured keratinocytes, in spite of the proteins being concentrated, reactivity around $40 \mathrm{kDa}$ was not observed, neither with MAbs nor with RA sera, indicating that the mature basic filaggrin was not expressed in vitro. At higher molecular weights, a diffuse reactivity above $100 \mathrm{kDa}$ was observed with the RA sera and with the three anti(pro)filaggrin MAbs. All the sera, including the controls, weakly recognized proteins of about 50 and 66 $\mathrm{kDa}$, which proved to be cytokeratins $\mathrm{Kl}$ and
$\mathrm{K} 10 / 11$ since they were also reactive with the MAb EE21-06. In the urea extracts from normal epidermis, the RA sera and the three anti(pro) filaggrin MAbs recognized a protein of about 37-40 kDa corresponding to the basic filaggrin. $\mathrm{AKHl}$ and AHFl exhibited an additional diffuse reactivity towards a high-molecular-weight antigen $>200 \mathrm{kDa}$, which corresponds to profilaggrin. Reactivity was not observed in this zone, neither with AHF7, which does not to recognize profilaggrin, nor with the RA sera. The control MAb EE21-06 and the human sera reacted with the cytokeratins in the 50-66 kDa zone. Some of the human sera and EE21-06 also exhibited an intense reactivity ranging from 66 to $>200 \mathrm{kDa}$. 


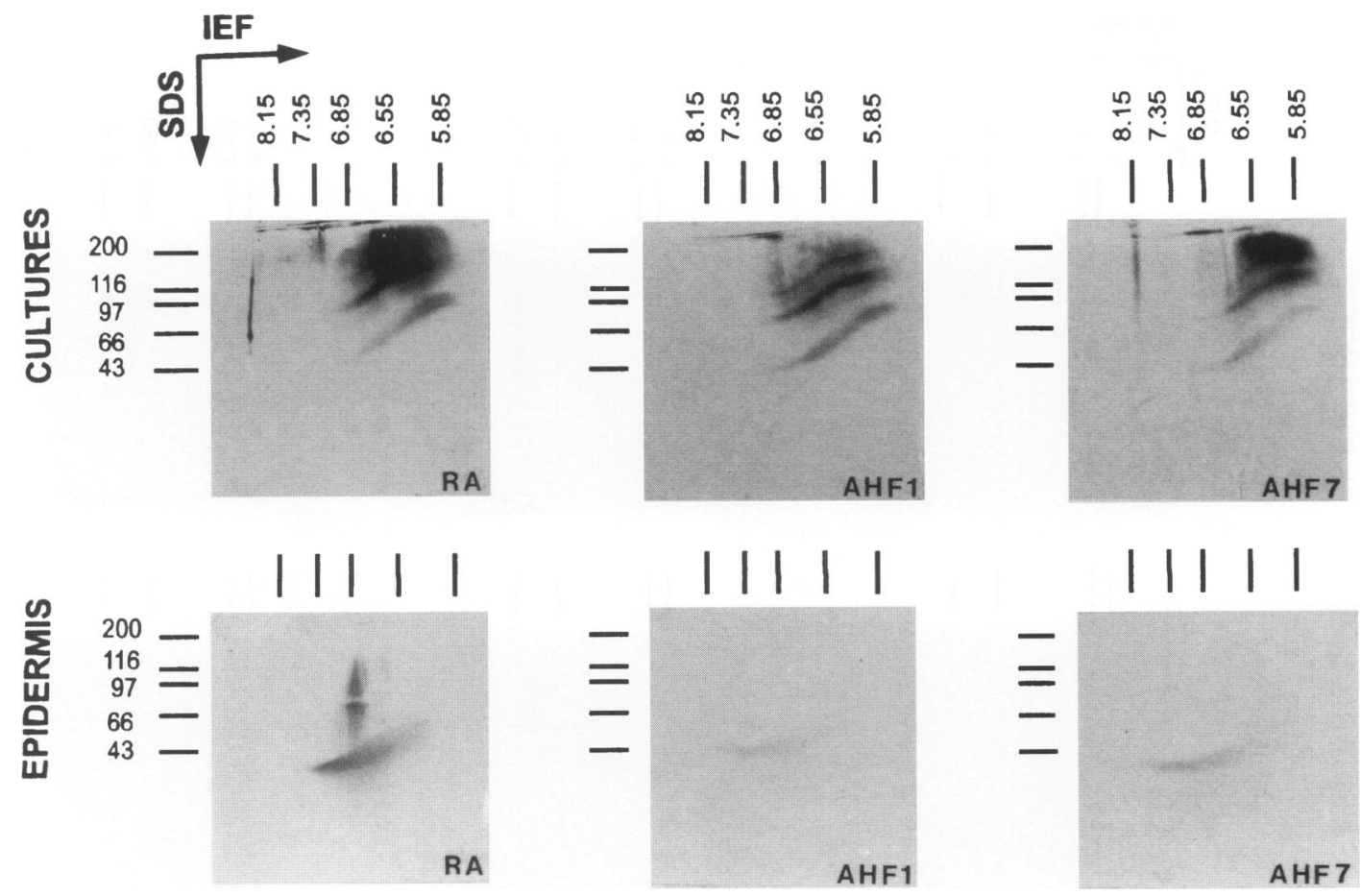

FIG. 4. Immunoblotting reactivity of RA serum and MAbs AHF1 and AHF7 on low-salt extracts of cultured keratinocytes and normal human epidermis separated by two-dimensional isoelectrofocusing/SDS-PAGE

In the extracts from cultured keratinocytes (upper half), the RA serum and the AHF monoclonal antibodies stain a series of antigens exhibiting an S-shaped migration pattern (pI ranging from 5.5 to 7.3 and molecular weights ranging from 40 up to $>200 \mathrm{kDa}$ ). In the extracts from normal epidermis (lower half), the RA serum and the AHF MAbs stain the comma-shaped neutral/acidic isoform of filaggrin (pI ranging from 6 to 7.4 and molecular weights ranging from 37 to $40 \mathrm{kDa}$ ). Molecular weight markers are on the left, pI markers are on the top of each membrane. IEF, isoelectrofocusing.

This reactivity resulted from cytokeratin aggregation, induced by overloading polyacrylamide gels to improve the sensitivity of immunodetection of (pro)filaggrin.

TWO-DIMENSIONAL IMMUNOBLOTTING ANALYSIS: LOWSalt Extracts (Fig. 4). In the cultured keratinocyte extracts, RA sera immunodetected a series of low-salt-soluble molecules exhibiting an Sshaped migration pattern. These molecules showed the same charge heterogeneity, with pI values ranging from 5.5 to 7.3 and increasing molecular weights ranging from 40 to above 200 $\mathrm{kDa}$. All the MAbs directed against (pro)filaggrin had a reactivity similar to that of the RA sera. In the control extracts from normal epidermis, both the RA sera and the AHF MAbs showed reactivity to a comma-shaped molecule located between 37 and $40 \mathrm{kDa}$ and with pI values ranging from 6 to 7.4. This molecule is the neutral/acidic isoform of epidermal filaggrin we recently described as the target of antikeratin antibodies (19). It partially colocalized with the S-shaped proteins of the lowest size, ranging from 40 to 70 $\mathrm{kDa}$. Thus, the RA-associated epitopes expressed in vitro are borne by several low-salt-soluble molecular forms of (pro)filaggrin, including in part the neutral/acidic filaggrin of normal human epidermis.

Urea Extracts (Fig. 5). The urea extracts were separated in nonequilibrium $\mathrm{pH}$ gel electrophoresis as the first dimension (since isoelectrofocusing separation would have caused the very basic filaggrin to leave the gel) and in SDS-PAGE as the second dimension. Reactivity to the 37-40 $\mathrm{kDa}$ basic filaggrin was not detected in the cultured epithelium extracts, neither with the RA sera nor with the AHF MAbs. However, the RA sera detected diffuse molecules with molecular 


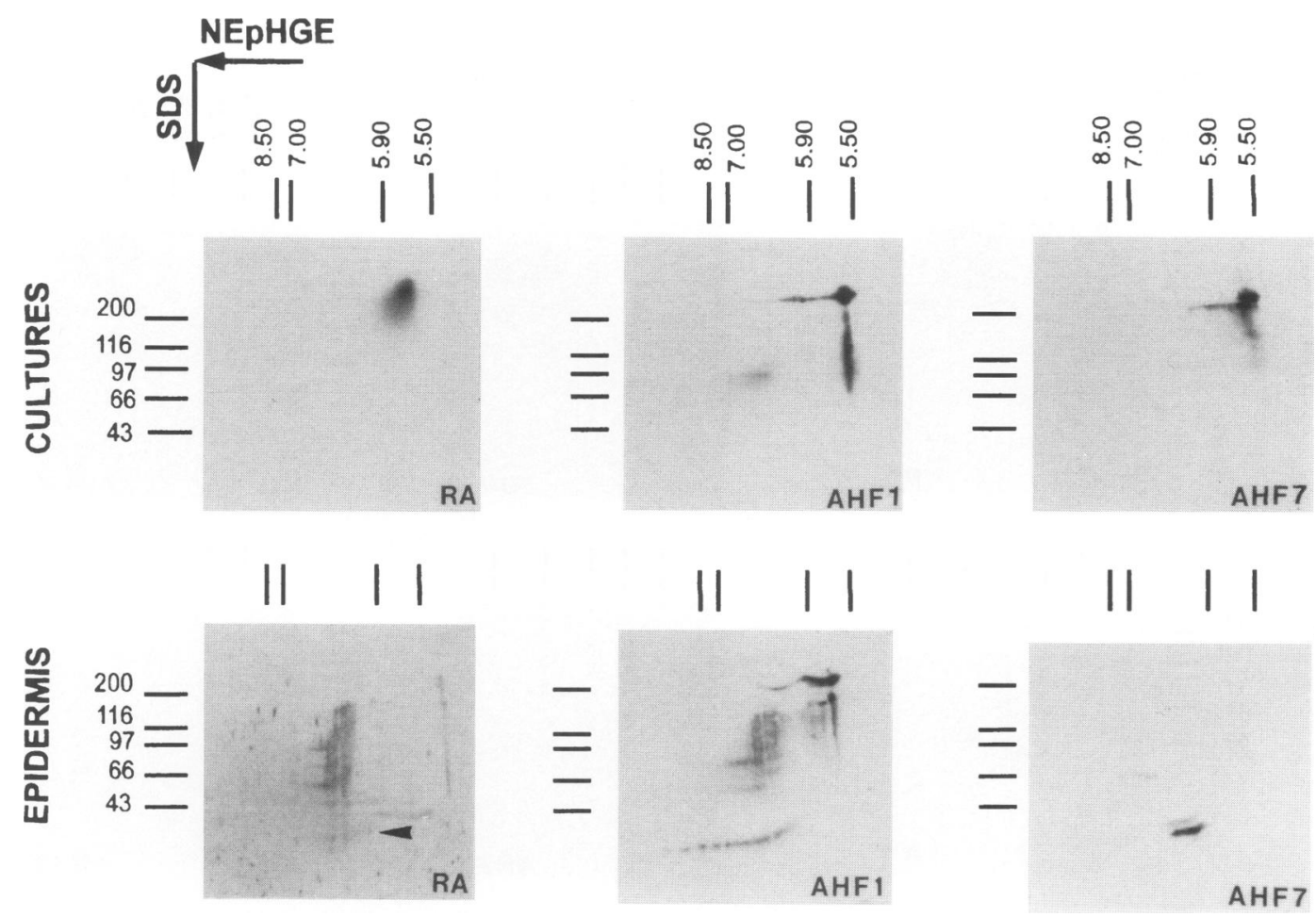

FIG. 5. Immunoblotting reactivity of RA serum and MAbs AHF1 and AHF7 on urea extracts of cultured keratinocytes and of normal human epidermis separated by two-dimensional nonequilibrium pH gel electrophoresis/SDS-PAGE

In the extracts from cultured keratinocytes (upper half), the RA serum and the AHF MAbs detect a diffuse protein spot (migration-like pI markers ranging from 5.4 to 5.9 and molecular weight above $100 \mathrm{kDa}$ ). AHF1 detects an additional group of molecules with lower molecular weight and more basic pI (ranging from 70 to $100 \mathrm{kDa}$ and from pI 6 to 7). In the extracts from normal epidermis (lower half), AHFl detects profilaggrin (molecular weight above $200 \mathrm{kDa}$ and pI from 5.4 to 5.9), comma-shaped filaggrin (molecular weight of $37-40 \mathrm{kDa}$ and $\mathrm{pI}$ from 6 to 9) and a series of molecules of intermediate size and charge. AHF7 detects a protein doublet corresponding to the most acidic part of the urea-soluble filaggrin. Like AHF7, the RA serum weakly detects the most acidic part of the urea-soluble filaggrin (arrowhead) and recognizes the same intermediate molecules between filaggrin and profilaggrin like AHFl. Molecular weight markers are on the left and migration of pI markers are on the top of each membrane. NEpHGE, nonequilibrium pH gel electrophoresis.

weights $>100 \mathrm{kDa}$ that migrated like protein markers with pIs ranging from 5.4 to 5.9 . These proteins were related to (pro)filaggrin since they were also detected by the anti-(pro)filaggrin MAbs. An additional group of molecules of lower molecular weights, from $70 \mathrm{kDa}$ to $100 \mathrm{kDa}$, and with more basic pIs, was detected only by AHFl. In the urea extracts obtained from epidermis, the acidic profilaggrin of $>200 \mathrm{kDa}$, the basic filaggrin of 37-40 kDa, and additional molecules of intermediate sizes and charges, were clearly identified with AKHl (not shown) and AHFl (Fig. 5). In contrast, AHF7 only detected a protein doublet corresponding to the most acidic fraction of the urea-soluble basic filaggrin. The RA sera did not recognize profilaggrin, but like AHF1, detected numerous molecules of sizes and charges that were intermediate between those of profilaggrin and filaggrin, and like AHF7, only the most acidic fraction of the urea-soluble basic filaggrin.

\section{DISCUSSION}

We have immunohistologically analyzed the reactivity of RA sera containing high titers of AFA toward cultured, normal epidermal keratinocytes. The keratinocytes were cultured in differentiating conditions, whereby epithelial sheets exhibiting a morphology roughly similar to that of epidermis were obtained. The RA sera labeled the cornified layers of the cultured epidermis, as observed on normal epidermis. However, the RA sera labeling of granules in the granular kerati- 
nocytes was not observed on normal epidermis (12). Double-staining experiments confirmed that the antigens recognized by the RA sera colocalized with the (pro)filaggrin recognized by the AKHl antibody, thus confirming that the labeled granules are keratohyalin granules. Consistent with this result, the AHF7 antibody, which is specific for an epitope borne by epidermal filaggrin and not by profilaggrin, did not label the epidermal keratohyalin granules but did label the granules of cultured epidermis. This suggests that the antigenic molecules expressed in vitro in the keratohyalin granules are different from the profilaggrin normally present in epidermal keratohyalin granules in vivo. The keratohyalin granules of cultured keratinocytes probably contain (pro)filaggrin-related molecules with antigenic determinants which are present on filaggrin in normal epidermis but are absent or masked on profilaggrin, the main component of keratohyalin granules.

In agreement with these immunohistochemical observations, new molecular forms of (pro) filaggrin were identified in the cultured epidermis by means of a sequential extraction procedure and immunoblotting. In the urea extracts of the cultured sheets, neither the AHF MAbs nor the RA sera immunodetected the mature basic epidermal filaggrin detected in normal epidermis. In contrast, all of them detected highmolecular-weight molecules sharing the biochemical characteristics of epidermal profilaggrin (molecular size, pI, and urea requirement for extraction). These molecules were nevertheless different from epidermal profilaggrin since they were recognized by the RA sera and by AHF7, both of which do not recognize the epidermal filaggrin precursor $(12,27)$. In the low-salt extracts from the cultured epidermis, AKHl, AHFl, AHF7, and the RA sera also recognized other (pro)filaggrin-related proteins that exhibited a wide heterogeneity in both charge and size. The low-salt- and urea-soluble (pro)filaggrin-related molecules probably result from various biochemical modifications of profilaggrin. Some of these molecules (probably the urea-soluble high-molecular-weight proteins) could be present in the keratohyalin granules, whereas others (probably the most processed, i.e., the lowest-molecularweight molecules extracted in a low-salt buffer) could be present in the stratum corneum and would be responsible for its labeling by AHF7 and the RA sera.

The two-dimensional electrophoresis migration of the low-salt-soluble antigenic proteins, as a series of molecules exhibiting the same $\mathrm{S}$-shaped pattern, resembles that of a multimeric system composed of monomeric proteins and various polymeric associations of these monomers. Similar S-shaped profilaggrin-related molecules were previously described by Asselineau et al. (33) using one-step urea extracts of human keratinocyte cultures grown in differentiating conditions. Aberrant migration due to extensive post-translational modifications could explain such an S-shaped pattern. The low-salt-soluble neutral/acidic isoform of filaggrin extracted from normal epidermis partially colocalized with the lowest size monomer extracted under the same conditions from the cultured epidermis. Thus, the multimeric system might correspond to molecules formed by one to 12 neutral/acidic filaggrin units. These molecules might accumulate in culture epidermis because of an interruption or decrease in profilaggrin processing which, in normal epidermis, involves several proteases and phosphatases (for a review, see ref. 23). A low level of phosphatase(s) activity in the cultured epidermis could cause an incomplete dephosphorylation of the precursor and therefore modify the susceptibility of the linker peptides to proteolysis, resulting in an accumulation of partially dephosphorylated and proteolyzed profilaggrin.

These immunohistological and immunochemical results show that the RA-associated antigenic molecules expressed in our cultures share the same characteristics of antigenic molecules previously identified in buccal epithelium and in epidermis. Indeed, some of the molecules expressed in vitro are located in the keratohyalin granules of the granular cells as in buccal epithelium. The high-molecular-weight, low-saltsoluble S-shaped molecules also exhibit similar biochemical properties to the $200-400 \mathrm{kDa}$ perinuclear antigen of the buccal epithelial cells (11). On the other hand, the 40-70 kDa $\mathrm{S}$-shaped protein partially comigrates in two-dimensional electrophoresis with the commashaped neutral/acidic filaggrin extracted from normal human epidermis. These data suggest that the cultured epithelial sheets in our in vitro model reach a stage of differentiation that is an intermediate between that of buccal epithelium and of epidermis, giving rise to new molecular forms of (pro)filaggrin.

The present study underlines the complexity of the events that occur during epidermal profilaggrin maturation. It illustrates the difficulty in obtaining basic filaggrin expression in cultures of 
human keratinocytes, owing to the difficulty in achieving terminal differentiation in vitro. The conversion of profilaggrin into mature filaggrin had been proposed to occur in human keratinocytes grown on a collagen matrix at the liquidair interface and after extensive removal of retinoids from the culture medium by serum delipidization (33). However, in this study, protein extraction with urea was performed as a one-step procedure, and filaggrin expression was determined by two-dimensional, nonequilibrium $\mathrm{pH}$ gel electrophoresis/SDS-PAGE. It is known that this method does not allow discrimination between the basic and the neutral/acidic isoforms of filaggrin. Evaluation of the pI range of the molecules extracted or isolation of a basic filaggrin by anionic exchange chromatography would be necessary to definitively conclude that mature basic filaggrin is indeed expressed in this type of culture. Regardless, this in vitro model will be useful to analyze the antigenicity of the molecules toward AFA.

Various factors are involved in the regulation of keratinocyte differentiation. In human epidermal keratinocytes cultured on emerged fibroblast-collagen lattices, retinoic acid was shown to be able to provoke metaplasia and to prevent keratinization of the tissue (34). Kautsky et al. (35) showed that this negative regulation of oral keratinocyte differentiation by retinoic acid could be modulated by the origin of the fibroblasts underlying the epithelial cells: fibroblasts from the noncornified zones of oral mucosa potentiated the effects of retinoic acid, compared with fibroblasts from cornified zones of the mucosa.

These data indicate that keratinocyte differentiation and consequently, profilaggrin processing are not only tissue-specific but also closely depend on the conditions of keratinocyte culture. This may explain the results obtained by Hoet and co-workers (36) that appear to contradict ours. These authors analyzed the expression of the antiperinuclear factor antigens in human buccal mucosa keratinocytes cultured on a $3 \mathrm{~T} 3$ fibroblast feeder layer that were induced to differentiate by addition of 12-O-tetradecanoylphorbol-13-acetate. This treatment induced the appearance of granules in the cultured buccal epithelial sheets and of (pro)filaggrin-related molecules in the granules. However, molecules reacting with RA sera were not detected. We assume that 12-O-tetradecanoylphorbol-13-acetate only allowed the expression in the keratohyalin granules of a molecular form of profilag- grin similar to phosphorylated epidermal profilaggrin and that, as in human epidermis, the molecule was recognized by AKHl, a monoclonal antibody to (pro)filaggrin, but not by RA sera. Further maturation of profilaggrin, which is necessary to generate the epitopes recognized by AFA, probably did not occur in this in vitro model. Pulse-chase labelings with ${ }^{32} \mathrm{P}$-orthophosphate on various models of keratinocyte cultures will allow us to test whether dephosphorylation is a crucial event in the appearance of the epitopes recognized by AFA on the (pro) filaggrin-related antigens. Such studies might also contribute to the elucidation of the mechanisms of profilaggrin maturation, which are well known in the mouse and the rat $(24,37-39)$, but poorly understood in humans.

In conclusion, we have described the antigenic molecules targeted by the RA-associated AFA, which are expressed by normal human epidermal keratinocytes cultured in differentiating conditions. We have shown that these molecules are immunologically and biochemically related to epidermal (pro)filaggrin and are exposed on keratohyalin granules, just as antiperinuclear factor antigens are exposed on keratohyalin granules of human buccal epithelial cells and borne by profilaggrin-related molecules. The identification of the epitopes recognized on the various differentiation-specific molecular forms of filaggrin and profilaggrin is now under investigation. This identification will allow the search of putative cross-reactive autoantigens in synoviocytes and chondrocytes. It will also help to illuminate the mechanism(s) of autoantibody production. Lastly, it might open the way toward specific immunosuppressive and/or preventive therapeutics of RA.

\section{ACKNOWLEDGMENTS}

We thank Professors A. Fournié and B. Fournié (Clinique de Rhumatologie, Hôpital Purpan, Toulouse) and Professors B. Mazières and A. Cantagrel (Service de Rhumatologie, Hôpital Rangueil, Toulouse) for providing patient data and sera. We also thank Professor M. Costagliola (Service de Chirurgie Plastique, Hôpital Rangueil, Toulouse) for providing samples of human skin. The technical assistance of M-P Cazevieille and M-F Isaïa is gratefully acknowledged. This study was supported by grants from the Université Paul Sabatier-Toulouse III (JEDGRT 1965), the Institut National de la Santé et 
de la Recherche Médicale (CRE-93-0205), the Région Midi-Pyrénées, the Fondation pour la Recherche Médicale, and the Association pour la Recherche sur la Polyarthrite.

\section{REFERENCES}

1. Wolfe F, Cathey MA, Roberts FK. (1991) The latex test revisited: Rheumatoid factor testing in 8287 rheumatic diseases patients. $A r$ thritis Rheum. 34: 951-960.

2. Steiner G, Hartmuth $\mathrm{K}$, Skiner $\mathrm{K}$, et al. (1992) Purification and partial sequencing of the nuclear autoantigen RA33 shows that it is indistinguishable from the A2 protein of the heterogeneous nuclear ribonucleoprotein complex. J. Clin. Invest. 90: 1061-1066.

3. Ferriss J, Cooper S, Roessner K, Hochberg M. (1990) Antibodies to denatured type II collagen in rheumatoid arthritis: negative association with IgM rheumatoid factor. J. Rheumatol. 17: 880-884.

4. Nienhuis RLF, Mandema E. (1964) A new serum factor in patients with rheumatoid arthritis: the antiperinuclear factor. Ann. Rheum. Dis. 23: 302-305.

5. Hoet RM, van Venrooij WJ. (1992) The antiperinuclear factor (APF) and antikeratin antibodies (AKA) in rheumatoid arthritis. In: Smolen JS, Kalden JR, Maini RN (eds). Rheumatoid Arthritis. Springer-Verlag, Berlin/Heidelberg, pp. 299-318.

6. Young BJJ, Mallya RK, Leslie RDG, Clarck CJM, Hamblin TJ. (1979) Anti-keratin antibodies in rheumatoid arthritis. Br. Med. J. 2: 97-99.

7. Quismorio FP Jr, Kaufman RL, Beardmore T, Mongan ES. (1983) Reactivity of serum antibodies to the keratin layer of rat œsophagus in patients with rheumatoid arthritis. Arthritis Rheum. 26: 494-499.

8. Miossec P, Youinou P, Le Goff P, Moineau MP. (1982) Clinical relevance of antikeratin antibodies in rheumatoid arthritis. Clin. Rheumatol. 1: 185-189.

9. Kirstein H, Mathiesen FK. (1987) Antikeratin antibodies in rheumatoid arthritis. Scand. J. Rheumatol. 16: 331-337.

10. Vincent C, Serre G, Lapeyre F, et al. (1989) High diagnostic value in rheumatoid arthritis of antibodies to the stratum corneum of rat œesophagus epithelium, so-called 'antikeratin antibodies'. Ann. Rheum. Dis. 48: 712722.
11. Sebbag M, Simon M, Vincent C, et al. (1995) The antiperinuclear factor and the so-called antikeratin antibodies are the same rheumatoid arthritis-specific autoantibodies. J. Clin. Invest. 95: 2672-2679.

12. Simon M, Vincent C, Haftek M, et al. (1995) The rheumatoid arthritis-associated autoantibodies to filaggrin label the fibrous matrix of the cornified cells but not the profilaggrincontaining keratohyalin granules in human epidermis. Clin. Exp. Immunol. 100: 90-98.

13. Serre G, Vincent C, Fournié B, Lapeyre F, Soleilhavoup J-P, Fournié A. (1986) Anticorps anti-stratum corneum d'oesophage de rat, auto-anticorps anti-kératines épidermiques et anti-épiderme dans la polyarthrite rhumatoïde et différentes affections rhumatologiques. Intérêt diagnostique, aspects fondamentaux. Rev. Rhum. Mal. Osteoartic 53: 607-614.

14. Johnson GD, Carvalho A, Holborow EJ, Goddard DH, Russel G. (1981) Antiperinuclear factor and keratin antibodies in rheumatoid arthritis. Ann. Rheum. Dis. 40: 263-266.

15. Youinou P, Le Goff $P$, Colaco CB, et al. (1985) Antikeratin antibodies in serum and synovial fluid show specificity for rheumatoid arthritis in a study of connective tissue diseases. Ann. Rheum. Dis. 44: 450-454.

16. Paimela L, Gripenberg $M$, Kurki P, LeirisaloRepo M. (1992) Antikeratin antibodies: Diagnostic and prognostic markers for early rheumatoid arthritis. Ann. Rheum. Dis. 51: 743-746.

17. Kurki $\mathrm{P}$, Aho $\mathrm{K}$, Palosuo T, Heliövaara M. (1992) Immunopathology of rheumatoid arthritis. Antikeratin antibodies precede the clinical disease. Arthritis Rheum. 35: 914917.

18. Girbal E and Sebbag $M$, Gomès-Daudrix V, Simon M, Vincent C, Serre G. (1993) Characterization of the rat œsophagus epithelium antigens defined by the so-called 'antikeratin antibodies', specific for rheumatoid arthritis. Ann. Rheum. Dis. 52: 749-757.

19. Simon M, Girbal E, Sebbag M, et al. (1993) The cytokeratin filament-aggregating protein filaggrin is the target of the so-called 'antikeratin antibodies', autoantibodies specific for rheumatoid arthritis. J. Clin. Invest. 92: 1387-1393.

20. Dale BA. (1977) Purification and characterization of a basic protein from the stratum 
corneum of mammalian epidermis. Biochim. Biophys. Acta 491: 193-204.

21. Lynley AM, Dale BA. (1983) Characterization of human epidermal filaggrin, a histidin-rich keratin filament aggregating protein. Biochim. Biophys. Acta 744: 28-35.

22. Lonsdale-Eccles JD, Hugen JA, Dale BA. (1980) A phosphorylated keratohyalin-derived precursor of epidermal stratum corneum basic protein. J. Biol. Chem. 255: 22352238.

23. Dale BA, Presland RB, Fleckman P, Kam E, Resing KA. (1993) Phenotype expression and processing of filaggrin in epidermal differentiation. In: Darman M, Blumenberg M (eds). Molecular Biology of the Skin. The Keratinocyte. Academic Press, San Diego, pp. 79105.

24. Scott IR, Harding CR. (1981) Studies on the synthesis and degradation of a high molecular weight histidine-rich phosphoprotein from mammalian epidermis. Biochim. Biophys. Acta 669: 65-78.

25. Navsaria H, Sexton C, Bouvard V, Leigh M. (1994) Growth of keratinocytes with a 3T3 feeder layer: Basic techniques. In: Leigh IL, Watt FM (eds). Keratinocyte Methods. Cambridge University Press, Cambridge, pp. $5-12$.

26. Rheinwald J, Green H. (1975) Formation of keratinizing epithelium in culture by a cloned cell line derived from a keratome. Cell 6: 331-344.

27. Simon M, Sebbag M, Haftek M, et al. (1995) Monoclonal antibodies to human epidermal filaggrin, some not recognizing profilaggrin. J. Invest. Dermatol. 105: 432-437.

28. Serre G, Mils V, Haftek M, et al. (1991) Identification of late differentiation antigens of human cornified epithelia, expressed in re-organized desmosomes and bound to cross-linked envelope. J. Invest. Dermatol. 97: 1061-1072.

29. Rothblat GH, Argogast LY, Ouelette L, Howard BV. (1976) Preparation of delipidized serum protein for use in cell culture systems. In Vitro 12: 554-557.

30. Arnett FC, Edworthy SM, Bloch DA, et al. (1988) The American Rheumatism Association 1987 revised criteria for the classifica- tion of rheumatoid arthritis. Arthritis Rheum. 31: 315-324.

31. Dale BA, Gown AM, Fleckman P, Kimball JR, Resing KA. (1987) Characterization of two monoclonal antibodies to epidermal keratohyalin: reactivity with filaggrin and related proteins. J. Invest. Dermatol. 88: 306313.

32. Serre G, Conter A, Ouhayoun J-P, et al. (1988) EE 21-06: A mouse monoclonal antibody to a sequential epitope common to the keratin polypeptides specifically expressed in human keratinized squamous epithelia. In: Rousset B (ed). Structure and Functions of the Cytoskeleton. Biological and Physiological Aspects. J Libbey Eurotext, London, Paris, Vol. 171, p. 524 [Abstr.].

33. Asselineau D, Dale BA, Bernard BA. (1990) Filaggrin production by cultured human epidermal keratinocytes and its regulation by retinoic acid. Differentiation 45: 221-229.

34. Asselineau D, Darmon M. (1995) Retinoic acid provokes metaplasia of epithelium formed in vitro by adult human epidermal keratinocytes. Differentiation 58: 297-306.

35. Kautsky MB, Fleckman P, Dale BA. (1995) Retinoic acid regulates oral epithelial differentiation by two mechanisms. J. Invest. Dermatol. 104: 546-553.

36. Hoet RM, Voorsmit RA, van Venrooij WJ. (1991) The perinuclear factor, a rheumatoid arthritis-specific antigen, is not present in the keratohyalin granules of cultured buccal mucosa cells. Clin. Exp. Immunol. 84: 59-65.

37. Resing KA, Johnson RS, Walsh KA. (1993) Characterization of protease processing sites during conversion of rat profilaggrin to filaggrin. Biochemistry 32: 10036-10045.

38. Resing KA, Walsh KA, Haugen-Scofield J, Dale BA. (1989) Identification of proteolytic cleavage sites in the conversion of profilaggrin to filaggrin in mammalian epidermis. J. Biol. Chem. 264: 1837-1845.

39. Resing KA, Al-Alawi N, Blomquist C, Fleckman P, Dale BA. (1993) Independent regulation of two cytoplasmic processing stages of the intermediate filament-associated protein filaggrin and role of $\mathrm{Ca}^{2+}$ in the second stage. J. Biol. Chem. 268: 25139-25145.

Communicated by N.A. Mitchison. Accepted on November 5, 1996. 